\title{
COMMON FIXED POINT THEOREMS FOR NONSELF-MAPPINGS IN METRICALLY CONVEX SPACES VIA ALTERING DISTANCES
}

\author{
M. IMDAD AND LADLAY KHAN
}

Received 13 January 2005 and in revised form 14 September 2005

Some common fixed point theorems for a pair of nonself-mappings in complete metrically convex metric spaces are proved by altering distances between the points, which generalize earlier results due to M. D. Khan and Bharadwaj (2001), M. S. Khan et al. (2000), Bianchini (1972), Chatterjea 1972, and others. Some related results are also discussed besides furnishing an illustrative example.

\section{Introduction}

There exists extensive literature on fixed points of self-mappings in metric and Banach spaces. But in many applications the mappings under examination may not always be self-mappings, therefore fixed point theorems for nonself-mappings form a natural subject for investigation. Assad and Kirk [2] initiated the study of fixed point of nonselfmappings in metrically convex spaces. Indeed while doing so, Assad and Kirk [2] noticed that with some kind of metric convexity, domain and range of the mappings under examination can be considered of more varied type. In recent years, this technique due to Assad and Kirk [2] has been utilized by many researchers of this domain and by now there exists considerable literature on this topic. To mention a few, we cite $[1,2,5,6,7,8,11$, $12]$.

Recently, Assad [1] gave sufficient conditions for nonself-mappings defined on a closed subset of complete metrically convex metric spaces satisfying Kannan-type mappings [10] which have been currently generalized by M. S. Khan et al. [12]. For the sake of completeness, we state the main result of M. S. Khan et al. [12].

Theorem 1.1. Let $(X, d)$ be a complete metrically convex metric space and $K$ a nonempty closed subset of $X$. Let $T: K \rightarrow X$ be a mapping satisfying the inequality

$$
d(T x, T y) \leq a \max \{d(x, T x), d(y, T y)\}+b\{d(x, T y)+d(y, T x)\}
$$


4030 Common fixed point theorems via altering distances

for every $x, y \in K$, where $a$ and $b$ are nonnegative reals such that

$$
\begin{gathered}
\max \left\{\frac{a+b}{1-b}, \frac{b}{1-a-b}\right\}=h>0, \\
\max \left\{\frac{1+a+b}{1-b} h, \frac{1+b}{1-a-b} h\right\}=h^{\prime}, \\
\max \left\{h, h^{\prime}\right\}=h^{\prime \prime}<1 .
\end{gathered}
$$

Further, if for every $x \in \delta K, T x \in K$, then $T$ has a unique fixed point in $K$.

\section{Preliminaries}

Before proving our results, we collect the relevant definitions and a lemma for our future use.

Definition 2.1 [5]. Let $K$ be a nonempty subset of a metric space $(X, d)$ and $F, T: K \rightarrow X$. The pair $(F, T)$ is said to be weakly commuting if for every $x, y \in K$ with $x=F y$ and $T y \in K$,

$$
d(T x, F T y) \leq d(T y, F y)
$$

Notice that for $K=X$, this definition reduces to that of Sessa [13].

Definition 2.2 [6]. Let $K$ be a nonempty subset of a metric space $(X, d)$ and $F, T: K \rightarrow X$. The pair $(F, T)$ is said to be compatible if for every sequence $\left\{x_{n}\right\} \subset K$ and from the relation

$$
\lim _{n \rightarrow \infty} d\left(F x_{n}, T x_{n}\right)=0
$$

and $T x_{n} \in K$ (for every $n \in \mathbb{N}$ ), it follows that

$$
\lim _{n \rightarrow \infty} d\left(T y_{n}, F T x_{n}\right)=0
$$

for every sequence $y_{n} \in K$ such that $y_{n}=F x_{n}, n \in \mathbb{N}$.

Notice that for $K=X$, this definition reduces to that of Jungck [9].

Definition 2.3. Let $(X, d)$ be a metric space and $K$ a nonempty subset of $X$. Let $F, T: K \rightarrow$ $X$ be a pair of maps which satisfy the condition

$$
\begin{aligned}
\phi(d(F x, F y)) \leq & a \max \left\{\frac{1}{2} \phi(d(T x, T y)), \phi(d(T x, F x)), \phi(d(T y, F y))\right\} \\
& +b\{\phi(d(T x, F y))+\phi(d(T y, F x))\}
\end{aligned}
$$

for all distinct $x, y \in K, a, b \geq 0$ such that $a+4 b<1$ and let $\phi: \mathbb{R}^{+} \rightarrow \mathbb{R}^{+}$be an increasing 
continuous function for which the following properties hold:

$$
\phi(t)=0 \Longleftrightarrow t=0, \quad \phi(2 t) \leq 2 \phi(t)
$$

Then $F$ is called generalized $T$ contraction mapping of $K$ into $X$.

Definition 2.4 [8]. A pair of nonself-mappings $(F, T)$ on a nonempty subset $K$ of a metric space $(X, d)$ is said to be coincidentally commuting if $T x, F x \in K$ and $T x=F x$ imply that $F T x=T F x$.

Definition 2.5 [2]. A metric space $(X, d)$ is said to be metrically convex if for any distinct $x, y \in X$, there exists a point $z \in X$ with $x \neq z \neq y$ such that

$$
d(x, z)+d(z, y)=d(x, y) .
$$

LEMMA 2.6 [2]. Let $K$ be a nonempty closed subset of a metrically convex metric space $X$. If $x \in K$ and $y \notin K$, then there exists a point $z \in \delta K$ (the boundary of $K$ ) such that

$$
d(x, z)+d(z, y)=d(x, y)
$$

\section{Results}

Our main result runs as follows.

Theorem 3.1. Let $(X, d)$ be a complete metrically convex metric space and $K$ a nonempty closed subset of $X$. If $F$ is a generalized $T$ contraction mapping of $K$ into $X$ satisfying the following:

(i) $\delta K \subseteq T K, F K \cap K \subseteq T K$,

(ii) $T x \in \delta K \Rightarrow F x \in K$,

(iii) $(F, T)$ is coincidentally commuting,

(iv) $T K$ is closed in $X$,

then $F$ and $T$ have a unique common fixed point.

Proof. Firstly, we proceed to construct two sequences $\left\{x_{n}\right\}$ and $\left\{y_{n}\right\}$ in the following way.

Let $x \in \delta K$. Then (due to $\delta K \subset T K$ ), there exists a point $x_{0} \in K$ such that $x=T x_{0}$. Since $T x \in \delta K \Rightarrow F x \in K$, one concludes that $F x_{0} \in F K \cap K \subseteq T K$. Let $x_{1} \in K$ be such that $y_{1}=T x_{1}=F x_{0} \in K$. Let $y_{2}=F x_{1}$. If $y_{2} \in K$, then $y_{2} \in F K \cap K \subseteq T K$ which implies that there exists a point $x_{2} \in K$ such that $y_{2}=T x_{2}$. If $y_{2} \notin K$, then there exists a point $p \in \delta K$ such that

$$
d\left(T x_{1}, p\right)+d\left(p, y_{2}\right)=d\left(T x_{1}, y_{2}\right)
$$

Since $p \in \delta K \subseteq T K$, there exists a point $x_{2} \in K$ such that $p=T x_{2}$ so that

$$
d\left(T x_{1}, T x_{2}\right)+d\left(T x_{2}, y_{2}\right)=d\left(T x_{1}, y_{2}\right)
$$

Thus, repeating the foregoing arguments, one obtains two sequences $\left\{x_{n}\right\}$ and $\left\{y_{n}\right\}$ such 
4032 Common fixed point theorems via altering distances

that

(v) $y_{n+1}=F x_{n}$

(vi) $y_{n} \in K \Rightarrow y_{n}=T x_{n}$ or $y_{n} \notin K \Rightarrow T x_{n} \in \delta K$ and

$$
d\left(T x_{n-1}, T x_{n}\right)+d\left(T x_{n}, y_{n}\right)=d\left(T x_{n-1}, y_{n}\right) \text {. }
$$

We denote

$$
\begin{aligned}
& P=\left\{T x_{i} \in\left\{T x_{n}\right\}: T x_{i}=y_{i}\right\} \\
& Q=\left\{T x_{i} \in\left\{T x_{n}\right\}: T x_{i} \neq y_{i}\right\}
\end{aligned}
$$

Obviously, the two consecutive terms cannot lie in $Q$.

Now, we distinguish the following three cases.

Case 1. If $T x_{n}, T x_{n+1} \in P$, then

$$
\begin{aligned}
\phi\left(d\left(T x_{n}, T x_{n+1}\right)\right)= & \phi\left(d\left(F x_{n-1}, F x_{n}\right)\right) \\
\leq & a \max \left\{\frac{1}{2} \phi\left(d\left(T x_{n-1}, T x_{n}\right)\right), \phi\left(d\left(T x_{n-1}, F x_{n-1}\right)\right), \phi\left(d\left(T x_{n}, F x_{n}\right)\right)\right\} \\
& +b\left\{\phi\left(d\left(T x_{n-1}, F x_{n}\right)\right)+\phi\left(d\left(T x_{n}, F x_{n-1}\right)\right)\right\} \\
= & a \max \left\{\phi\left(d\left(y_{n-1}, y_{n}\right)\right), \phi\left(d\left(y_{n}, y_{n+1}\right)\right)\right\}+b \phi\left(d\left(y_{n-1}, y_{n+1}\right)\right) \\
= & a \max \left\{\phi\left(d\left(y_{n-1}, y_{n}\right)\right), \phi\left(d\left(y_{n}, y_{n+1}\right)\right)\right\} \\
& +b \phi\left\{2 \max \left[d\left(y_{n-1}, y_{n}\right), d\left(y_{n}, y_{n+1}\right)\right]\right\},
\end{aligned}
$$

which in turn yields

$$
\phi\left(d\left(T x_{n}, T x_{n+1}\right)\right) \leq \begin{cases}\left(\frac{a+b}{1-b}\right) \phi\left(d\left(T x_{n-1}, T x_{n}\right)\right), & \text { if } d\left(y_{n-1}, y_{n}\right) \geq d\left(y_{n+1}, y_{n}\right) \\ 0, & \text { if } d\left(y_{n-1}, y_{n}\right) \leq d\left(y_{n+1}, y_{n}\right)\end{cases}
$$

Case 2. If $T x_{n} \in P$ and $T x_{n+1} \in Q$, then

$$
d\left(T x_{n}, T x_{n+1}\right)+d\left(T x_{n+1}, y_{n+1}\right)=d\left(T x_{n}, y_{n+1}\right),
$$

which in turn yields

$$
d\left(T x_{n}, T x_{n+1}\right) \leq d\left(T x_{n}, y_{n+1}\right)=d\left(y_{n}, y_{n+1}\right),
$$

and hence

$$
\phi\left(d\left(T x_{n}, T x_{n+1}\right)\right) \leq \phi\left(d\left(T x_{n}, y_{n+1}\right)\right)=\phi\left(d\left(y_{n}, y_{n+1}\right)\right) .
$$


Now, as in Case 1, one obtains

$$
\phi\left(d\left(T x_{n}, T x_{n+1}\right)\right) \leq \begin{cases}\left(\frac{a+b}{1-b}\right) \phi\left(d\left(T x_{n-1}, T x_{n}\right)\right), & \text { if } d\left(y_{n-1}, y_{n}\right) \geq d\left(y_{n+1}, y_{n}\right) \\ 0, & \text { if } d\left(y_{n-1}, y_{n}\right) \leq d\left(y_{n+1}, y_{n}\right) .\end{cases}
$$

Case 3. If $T x_{n} \in Q$ and $T x_{n+1} \in P$, then $T x_{n-1} \in P$. Since $T x_{n}$ is a convex linear combination of $T x_{n-1}$ and $y_{n}$, it follows that

$$
d\left(T x_{n}, T x_{n+1}\right) \leq \max \left\{d\left(T x_{n-1}, T x_{n+1}\right), d\left(y_{n}, T x_{n+1}\right)\right\}
$$

Now, if $d\left(T x_{n-1}, T x_{n+1}\right) \leq d\left(y_{n}, T x_{n+1}\right)$, then proceeding as in Case 1, we have

$$
\phi\left(d\left(T x_{n}, T x_{n+1}\right)\right) \leq \begin{cases}\left(\frac{a+b}{1-b}\right) \phi\left(d\left(T x_{n-1}, T x_{n}\right)\right), & \text { if } d\left(y_{n-1}, y_{n}\right) \geq d\left(y_{n+1}, y_{n}\right) \\ 0, & \text { if } d\left(y_{n-1}, y_{n}\right) \leq d\left(y_{n+1}, y_{n}\right)\end{cases}
$$

On the other hand, if $d\left(T x_{n}, T x_{n+1}\right) \leq d\left(T x_{n-1}, T x_{n+1}\right)$, then

$$
\begin{aligned}
\phi\left(d\left(T x_{n}, T x_{n+1}\right)\right) \leq & \phi\left(d\left(T x_{n-1}, T x_{n+1}\right)\right)=\phi\left(d\left(F x_{n-2}, F x_{n}\right)\right) \\
\leq & a \max \left\{\frac{1}{2} \phi\left(d\left(T x_{n-2}, T x_{n}\right)\right), \phi\left(d\left(T x_{n-2}, F x_{n-2}\right)\right), \phi\left(d\left(T x_{n}, F x_{n}\right)\right)\right\} \\
& +b\left\{\phi\left(d\left(T x_{n-2}, F x_{n}\right)\right)+\phi\left(d\left(T x_{n}, F x_{n-2}\right)\right)\right\} \\
= & a \max \left\{\frac{1}{2} \phi\left(d\left(y_{n-2}, T x_{n}\right)\right), \phi\left(d\left(y_{n-2}, y_{n-1}\right)\right), \phi\left(d\left(T x_{n}, y_{n+1}\right)\right)\right\} \\
& +b\left\{\phi\left(d\left(y_{n-2}, y_{n+1}\right)\right)+\phi\left(d\left(T x_{n}, y_{n-1}\right)\right)\right\} .
\end{aligned}
$$

Since

$$
\begin{aligned}
\frac{1}{2} \phi\left(d\left(y_{n-2}, T x_{n}\right)\right) & =\frac{1}{2}\left\{\phi\left(d\left(y_{n-2}, y_{n-1}\right)+d\left(y_{n-1}, T x_{n}\right)\right)\right\} \\
& =\max \left\{\phi\left(d\left(T x_{n}, y_{n-1}\right)\right), \phi\left(d\left(y_{n-1}, y_{n-2}\right)\right)\right\},
\end{aligned}
$$

therefore, one gets

$$
\begin{aligned}
\phi\left(d\left(T x_{n}, T x_{n+1}\right)\right)= & a \max \left\{\phi\left(d\left(T x_{n}, y_{n-1}\right)\right), \phi\left(d\left(y_{n-1}, y_{n-2}\right)\right), \phi\left(d\left(T x_{n}, y_{n+1}\right)\right)\right\} \\
& +b\left\{\phi\left(d\left(y_{n-2}, y_{n+1}\right)\right)+\phi\left(d\left(T x_{n}, y_{n-1}\right)\right)\right\} .
\end{aligned}
$$


4034 Common fixed point theorems via altering distances

Note that by Case 2 , we have $\phi\left(d\left(T x_{n-1}, T x_{n}\right)\right) \leq \phi\left(d\left(T x_{n-2}, T x_{n-1}\right)\right)$, therefore

$$
\begin{aligned}
\phi\left(d\left(T x_{n}, T x_{n+1}\right)\right) \leq & a \max \left\{\phi\left(d\left(y_{n-1}, y_{n-2}\right)\right), \phi\left(d\left(T x_{n}, y_{n+1}\right)\right)\right\} \\
& +b \phi\left(d\left(y_{n-2}, y_{n+1}\right)\right)+b \phi\left(d\left(y_{n-2}, y_{n-1}\right)\right) \\
\leq & a \max \left\{\phi\left(d\left(y_{n-1}, y_{n-2}\right)\right), \phi\left(d\left(T x_{n}, y_{n+1}\right)\right)\right\} \\
& +b \phi\left[3 \max \left\{d\left(y_{n-2}, y_{n-1}\right), d\left(y_{n-1}, T x_{n}\right), d\left(T x_{n}, y_{n+1}\right)\right\}\right] \\
& +b \phi\left(d\left(y_{n-2}, y_{n-1}\right)\right)
\end{aligned}
$$

which in turn yields

$$
\begin{aligned}
& \phi\left(d\left(T x_{n}, T x_{n+1}\right)\right) \\
& \quad \leq \begin{cases}\left(\frac{a+3 b}{1-b}\right) \phi\left(d\left(T x_{n-2}, T x_{n-1}\right)\right), & \text { if } d\left(y_{n-2}, y_{n-1}\right) \geq d\left(T x_{n}, y_{n+1}\right), \\
\left(\frac{b}{1-a-3 b}\right) \phi\left(d\left(T x_{n-2}, T x_{n-1}\right)\right), & \text { if } d\left(y_{n-2}, y_{n-1}\right) \leq d\left(T x_{n}, y_{n+1}\right) .\end{cases}
\end{aligned}
$$

Thus in all cases, we have

$$
\phi\left(d\left(T x_{n}, T x_{n+1}\right)\right) \leq k \max \left\{\phi\left(d\left(T x_{n-1}, T x_{n}\right)\right), \phi\left(d\left(T x_{n-2}, T x_{n-1}\right)\right)\right\},
$$

where $k=\max \{((a+b) /(1-b)),((a+3 b) /(1-b))\}$.

It can be easily shown by induction that for $n \geq 1$, we have

$$
\phi\left(d\left(T x_{n}, T x_{n+1}\right)\right) \leq k^{n} \max \left\{\phi\left(d\left(T x_{0}, T x_{1}\right)\right), \phi\left(d\left(T x_{1}, T x_{2}\right)\right)\right\} .
$$

Now, for any positive integer $p$, we have

$$
\begin{aligned}
\phi\left(d\left(T x_{n}, T x_{n+p}\right)\right) & \leq \phi\left\{d\left(T x_{n}, T x_{n+1}\right)+d\left(T x_{n+1}, T x_{n+2}\right)+\cdots+d\left(T x_{n+p-1}, T x_{n+p}\right)\right\} \\
& \leq \phi\left[\left\{1+k+k^{2}+\cdots+k^{p-1}\right\} k^{n} \max \left\{d\left(T x_{0}, T x_{1}\right), d\left(T x_{1}, T x_{2}\right)\right\}\right] \\
& \leq \phi\left[\left\{\frac{1}{1-k}\right\} k^{n} \max \left\{d\left(T x_{0}, T x_{1}\right), d\left(T x_{1}, T x_{2}\right)\right\}\right],
\end{aligned}
$$

which implies that $\phi\left(d\left(T x_{n}, T x_{n+1}\right)\right) \rightarrow 0$ as $n \rightarrow \infty$, so that $\left\{T x_{n}\right\}$ is a Cauchy sequence and hence converges to a point $z$ in $X$. We assume that a subsequence $\left\{T x_{n_{k}}\right\}$ of $\left\{T x_{n}\right\}$ contained in $P$ and $T K$ is a closed subspace of $X$. Since $\left\{T x_{n_{k}}\right\}$ is Cauchy in $T K$, it converges to a point $z \in T K$. Let $u \in T^{-1} z$; then $T u=z$. Here, one also needs to note that $\left\{F x_{n_{k}-1}\right\}$ will also converge to $z$.

Using (2.4), one can write

$$
\begin{aligned}
\phi\left(d\left(F x_{n_{k}-1}, F u\right)\right) \leq & a \max \left\{\frac{1}{2} \phi\left(d\left(T x_{n_{k}-1}, T u\right)\right), \phi\left(d\left(T x_{n_{k}-1}, F x_{n_{k}-1}\right)\right), \phi(d(T u, F u))\right\} \\
& +b\left\{\phi\left(d\left(F x_{n_{k}-1}, T u\right)\right)+\phi\left(d\left(F u, T x_{n_{k}-1}\right)\right)\right\}
\end{aligned}
$$


which, on letting $k \rightarrow \infty$, reduces to

$$
\begin{gathered}
\phi(d(F u, z)) \leq a \max \left\{\frac{1}{2} \phi(d(T u, z)), 0, \phi(d(T u, F u))\right\}+b\{\phi(d(T u, z))+\phi(d(F u, z))\}, \\
\phi(d(F u, T u)) \leq(a+b) \phi(d(F u, T u)),
\end{gathered}
$$

yielding thereby $T u=F u$ which shows that $u$ is a point of coincidence for $F$ and $T$.

Since the pair $(F, T)$ is coincidentally commuting, therefore

$$
z=T u=F u \Longrightarrow F z=F T u=T F u=T z .
$$

To prove that $z$ is the fixed point of $F$, consider

$$
\begin{aligned}
\phi(d(F z, z))= & \phi(d(F z, F u)) \\
\leq & a \max \left\{\frac{1}{2} \phi(d(T z, T u)), \phi(d(T z, F z)), \phi(d(T u, F u))\right\} \\
& +b\{\phi(d(T z, F u))+\phi(d(T u, F z))\} \\
\leq & \left(\frac{a}{2}+2 b\right) \phi(d(F z, z)),
\end{aligned}
$$

which shows that $z$ is a common fixed point of $F$ and $T$. The proof goes on similar lines in case we assume subsequence $\left\{T x_{n_{k}}\right\}$ of $\left\{T x_{n}\right\}$ contained in $Q$, hence it is omitted. The uniqueness of fixed point follows easily. This completes the proof.

Remark 3.2. By setting $T=I_{K}$ and $\phi(t)=t$, one deduces a result similar to the main results of M. S. Khan et al. [12] and M. D. Khan and Bharadwaj [11].

Remark 3.3. By restricting $T=I_{K}$ and $\phi(t)=t$ with $b=0$, one deduces a result for nonself-mappings satisfying Bianchini-type condition [3].

Remark 3.4. If we choose $T=I_{K}$ and $\phi(t)=t$ with $a=0$, then, one deduces a result for nonself-mappings satisfying Chatterjea-type condition [4].

Inspired by Imdad [7], we derive a corollary (as an application of Theorem 3.1) which involves self- as well as nonself-mappings.

Corollary 3.5. Let $I, J: K \rightarrow K, F: I(K) \rightarrow X$, and $T: J(K) \rightarrow X$ be four mappings so that $F I$ and $T J$ are nonself-mappings from a closed subset $K$ to $X$ which satisfy the condition

$$
\begin{aligned}
\phi(d(F I x, F I y)) \leq & a \max \left\{\frac{1}{2} \phi(d(T J x, T J y)), \phi(d(T J x, F I x)), \phi(d(T J y, F I y))\right\} \\
& +b\{\phi(d(T J x, F I y))+\phi(d(T J y, F I x))\},
\end{aligned}
$$

for all $x, y \in K$ with $x \neq y, a, b \geq 0$ such that $a+4 b<1$, and let $\phi: \mathbb{R}^{+} \rightarrow \mathbb{R}^{+}$be an increasing continuous function which satisfies $\phi(t)=0 \Leftrightarrow t=0$ and $\phi(2 t) \leq 2 \phi(t)$. Suppose that

(vii) $\delta K \subseteq T J K, F I K \cap K \subseteq T J K$,

(viii) $T J x \in \delta K \Rightarrow F I x \in K$,

(ix) $T J K$ is closed in $X$. 


\section{Common fixed point theorems via altering distances}

Then $(F I, T J)$ has a point of coincidence $z$. Furthermore, if the pair $(F I, T J)$ is coincidentally commuting, then $z$ is also the unique common fixed point of FI and TJ. Moreover, if the pairs $(F, I),(F I, I),(T, J),(T J, J),(F I, T),(F I, J),(T J, F)$, and $(T J, I)$ commute at $z$, then $z$ remains a common fixed point of $F, I, T$, and $J$.

Proof. Since all the conditions of Theorem 3.1 are satisfied, therefore FI and TJ have a unique common fixed point $z$. Now, using the commutativity of various pairs, one can easily show that $z$ remains the unique common fixed point of $F, I, T$, and $J$.

In the next theorem, we use "weak commutativity" instead of "coincidentally commuting property" of $(F, T)$ and alternately replace the "closedness of $T K$ " by "continuity of the map $F$ or $T$ " to prove the following.

Theorem 3.6. Let $(X, d)$ be a complete metrically convex metric space and $K$ a nonempty closed subset of $X$. Let $F, T: K \rightarrow X$ be a pair of maps which satisfy (2.4), (i), and (ii). Suppose that

(x) $(F, T)$ is a weakly commuting pair,

(xi) either $F$ or $T$ is continuous on $K$.

Then $F$ and $T$ have a unique common fixed point.

Proof. On the lines of the proof of Theorem 3.1, one can show that the sequence $\left\{T x_{n}\right\}$ converges to a point $z$ in $X$. Assume that there exists a subsequence $\left\{T x_{n_{k}}\right\}$ of $\left\{T x_{n}\right\}$ which is contained in $P$. Since $T$ is continuous, $\left\{T T x_{n_{k}}\right\}$ converges to a point $T z$. As $F x_{n_{k}-1}=T x_{n_{k}}$ and $T x_{n_{k}-1} \in K$, on using the weak commutativity of $(F, T)$, we have

$$
d\left(T T x_{n_{k}}, F T x_{n_{k}-1}\right) \leq d\left(F x_{n_{k}-1}, T x_{n_{k}-1}\right)
$$

which, on letting $k \rightarrow \infty$, reduces to $d\left(T z, F T x_{n_{k}-1}\right) \rightarrow 0$.

Using (2.4), one can write

$$
\begin{aligned}
& \phi\left(d\left(F T x_{n_{k}-1}, F z\right)\right) \\
& \leq a \max \left\{\frac{1}{2} \phi\left(d\left(T T x_{n_{k}-1}, T z\right)\right), \phi\left(d\left(T T x_{n_{k}-1}, F T x_{n_{k}-1}\right)\right), \phi(d(T z, F z))\right\} \\
&+b\left\{\phi\left(d\left(T T x_{n_{k}-1}, F z\right)\right)+\phi\left(d\left(T z, F T x_{n_{k}-1}\right)\right)\right\},
\end{aligned}
$$

which, on letting $k \rightarrow \infty$, reduces to

$$
\begin{aligned}
\phi(d(T z, F z)) & \leq a \max \{0,0, \phi(d(T z, F z))\}+b\{\phi(d(F z, T z))+0\} \\
& \leq(a+b) \phi(d(T z, F z)),
\end{aligned}
$$

yielding thereby $F z=T z$. 
To prove that $z$ is the fixed point of $T$, consider

$$
\begin{aligned}
\phi\left(d\left(T x_{n_{k}}, T z\right)\right)= & \phi\left(d\left(F x_{n_{k}-1}, F z\right)\right) \\
\leq & a \max \left\{\frac{1}{2} \phi\left(d\left(T x_{n_{k}-1}, T z\right)\right), \phi\left(d\left(T x_{n_{k}-1}, F x_{n_{k}-1}\right)\right), \phi(d(T z, F z))\right\} \\
& +b\left\{\phi\left(d\left(T x_{n_{k}-1}, F z\right)\right)+\phi\left(d\left(T z, F x_{n_{k}-1}\right)\right)\right\}
\end{aligned}
$$

which, on letting $k \rightarrow \infty$, reduces to

$$
\phi(d(T z, z)) \leq\left(\frac{a}{2}+2 b\right) \phi(d(T z, z))
$$

implying thereby that $z=T z$. Thus $z=T z=F z$, which shows that $z$ is a common fixed point of $F$ and $T$. In case the subsequence $\left\{T x_{n_{k}}\right\}$ of $\left\{T x_{n}\right\}$ is contained in $Q$, then the proof goes on similar lines, hence it is omitted. This completes the proof.

Finally, we prove a theorem when "weak commutativity" is replaced by "compatibility."

Theorem 3.7. Let $(X, d)$ be a complete metrically convex metric space and $K$ a nonempty closed subset of $X$. Let $F, T: K \rightarrow X$ be a pair of maps satisfying (2.4), (i), and (ii). Suppose that

(xii) $(F, T)$ is a compatible pair,

(xiii) $F$ and $T$ are continuous on $K$.

Then $F$ and $T$ have a unique common fixed point.

Proof. On the lines of the proof of Theorem 3.1, one can show that the sequence $\left\{T x_{n}\right\}$ converges to a point $z \in K$. Again, we assume that a subsequence $\left\{T x_{n_{k}}\right\}$ of $\left\{T x_{n}\right\}$ is contained in $P$. Since $T x_{n_{k}}=F x_{n_{k}-1}$ and $T x_{n_{k}-1} \in K$, using compatibility of $(F, T)$, we have

$$
\lim _{n \rightarrow \infty} d\left(F x_{n_{k}-1}, T x_{n_{k}-1}\right)=0, \quad \lim _{n \rightarrow \infty} d\left(T T x_{n_{k}}, F T x_{n_{k}-1}\right)=0
$$

Using continuity of $T$, it follows that $\left\{F T x_{n_{k}-1}\right\} \rightarrow T z$ as $k \rightarrow \infty$. Now, repeating the foregoing arguments (as in Theorem 3.6), one can show that $z=T z=F z$. This completes the proof.

Remark 3.8. Corollaries similar to Corollary 3.5 can be outlined in the context of Theorems 3.6 and 3.7 .

\section{An illustrative example}

Finally, we furnish an example to establish the utility of our results over earlier ones especially those contained in $[3,4,11,12]$ and others. 
4038 Common fixed point theorems via altering distances

Example 4.1. Let $\mathbb{R}$ be the set of reals equipped with usual metric, $K=\{-2\} \cup[0,1]$. Define $F, T: K \rightarrow X$ by

$$
T x=\left\{\begin{array}{ll}
-2 x & \text { if } 0 \leq x \leq 1, \\
1 & \text { if } x=-2,
\end{array} \quad F x= \begin{cases}-\frac{x}{2} & \text { if } 0 \leq x<1 \\
0 & \text { if } x \in\{-2,1\}\end{cases}\right.
$$

whereas $\phi: \mathbb{R}^{+} \rightarrow \mathbb{R}^{+}$is defined by $\phi(t)=t$.

Since $\delta K$ (the boundary of $K)=\{-2,0,1\}$ and $T K=[-2,0] \cup\{1\}$ which is also closed in $\mathbb{R}$, clearly $\delta K \subseteq T K$. Furthermore, $F K=(-1 / 2,0] \Rightarrow K \cap F K=\{0\} \subset T K$.

Also

$$
\begin{gathered}
T 1=-2 \in \delta K \Longrightarrow F 1=0 \in K, \\
T 0=0 \in \delta K \Longrightarrow F 0=0 \in K, \\
T(-2)=1 \in \delta K \Longrightarrow F(-2)=0 \in K .
\end{gathered}
$$

Now, if $x, y \in[0,1)$, then

$$
\begin{aligned}
\phi(d(F x, F y))= & \frac{1}{2}|x-y|=\frac{1}{2}\left(\frac{1}{2} d(T x, T y)\right) \\
\leq & \frac{2}{3} \max \left\{\frac{1}{2} d(T x, T y), d(T x, F x), d(T y, F y)\right\} \\
& +\frac{1}{16}\{d(T x, F y)+d(F x, T y)\} .
\end{aligned}
$$

Next, if $x \in[0,1)$ and $y=-2$, then

$$
\begin{aligned}
\phi(d(F x, F y))= & \frac{x}{2}=\frac{1}{3}\left(\frac{3 x}{2}\right)=\frac{1}{3} d(T x, F x) \\
\leq & \frac{2}{3} \max \left\{\frac{1}{2} d(T x, T y), d(T x, F x),(T y, F y)\right\} \\
& +\frac{1}{16}\{d(T x, F y)+d(F x, T y)\} .
\end{aligned}
$$

Finally, if $x=1$ and $y=-2$, then

$$
\begin{aligned}
\phi(d(F x, F y))=0 \leq & \frac{2}{3} \max \left\{\frac{1}{2} d(T x, T y), d(T x, F x),(T y, F y)\right\} \\
& +\frac{1}{16}\{d(T x, F y)+d(F x, T y)\},
\end{aligned}
$$

which shows that the contraction condition (2.4) is satisfied for every distinct $x, y \in K$. Moreover " 0 " is a point of coincidence as $T 0=F 0$. Also $T F 0=0=F T 0$; hence the pair $(F, T)$ is coincidentally commuting. Thus all the conditions of Theorem 3.1 are satisfied and " 0 " is the unique common fixed point of $F$ and $T$.

However, it is interesting to note that Theorem 1.1 due to M. S. Khan et al. [12] (also Theorem 1 due to M. D. Khan and Bharadwaj [11]) does not work in the context of 
mapping T. Otherwise, for $x=1, y=-2$ (making use of $((a+b) /(1-b))<1$ or $(b /(1-$ $a-b))<1$, contraction condition $(1.1)$ reduces to

$$
3<a \max \{3,3\}+2 b<3 a+2 \frac{1-a}{2}<2 a+1
$$

implying thereby that $a>1$ which is indeed a contradiction to the fact that $a<1$. Here, it is worth noting that the mappings $T$ and $F$ satisfying (2.4) need not satisfy (1.1) separately (e.g., mapping $T$ ) which establishes the utility of our results proved in this paper.

\section{Acknowledgments}

The authors are grateful to the learned referees for critical reading of the entire manuscript and suggesting many improvements. The first author is also grateful to the University Grants Commission in India for the financial assistance (Project no. F.30-246/2004 $(\mathrm{SR})$ ).

\section{References}

[1] N. A. Assad, On a fixed point theorem of Kannan in Banach spaces, Tamkang J. Math. 7 (1976), no. 1, 91-94.

[2] N. A. Assad and W. A. Kirk, Fixed point theorems for set-valued mappings of contractive type, Pacific J. Math. 43 (1972), no. 3, 553-562.

[3] R. M. Bianchini, Su un problema di S. Reich riguardante la teoria dei punti fissi, Boll. Un. Mat. Ital. (4) 5 (1972), 103-108.

[4] S. K. Chatterjea, Fixed-point theorems, C. R. Acad. Bulgare Sci. 25 (1972), 727-730.

[5] O. Hadžić, On coincidence points in convex metric spaces, Univ. u Novom Sadu Zb. Rad. Prirod.Mat. Fak. Ser. Mat. 19 (1989), no. 2, 233-240.

[6] O. Hadžić and Lj. Gajić, Coincidence points for set-valued mappings in convex metric spaces, Univ. u Novom Sadu Zb. Rad. Prirod.-Mat. Fak. Ser. Mat. 16 (1986), no. 1, 13-25.

[7] M. Imdad, Remarks on fixed point theorems for nonself mappings, Aligarh Bull. Math. 22 (2003), no. $1,15-17$.

[8] M. Imdad and S. Kumar, Boyd and Wong type theorems for two pairs of non-self mappings, Nonlinear Anal. Forum 8 (2003), no. 1, 69-78.

[9] G. Jungck, Compatible mappings and common fixed points, Int. J. Math. Math. Sci. 9 (1986), no. $4,771-779$.

[10] R. Kannan, Some results on fixed points, Bull. Calcutta Math. Soc. 60 (1968), 71-76.

[11] M. D. Khan and R. Bharadwaj, A fixed point theorem in metrically convex space, Indian J. Math. 43 (2001), no. 3, 373-379.

[12] M. S. Khan, H. K. Pathak, and M. D. Khan, Some fixed point theorems in metrically convex spaces, Georgian Math. J. 7 (2000), no. 3, 523-530.

[13] S. Sessa, On a weak commutativity condition of mappings in fixed point considerations, Publ. Inst. Math. (Beograd) (N.S.) 32(46) (1982), 149-153.

M. Imdad: Department of Mathematics, Aligarh Muslim University, Aligarh 202 002, India

E-mail address: mhimdad@yahoo.co.in

Ladlay Khan: Department of Mathematics, Aligarh Muslim University, Aligarh 202 002, India

E-mail address: k_ladlay@yahoo.com 


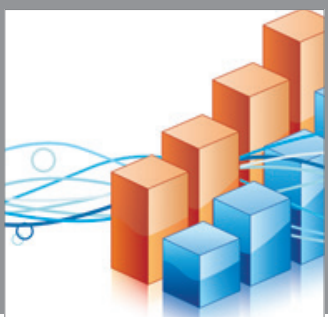

Advances in

Operations Research

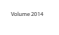

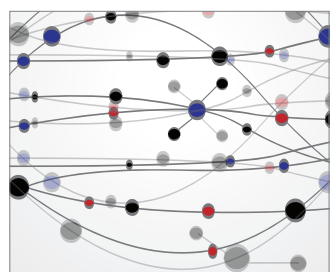

\section{The Scientific} World Journal
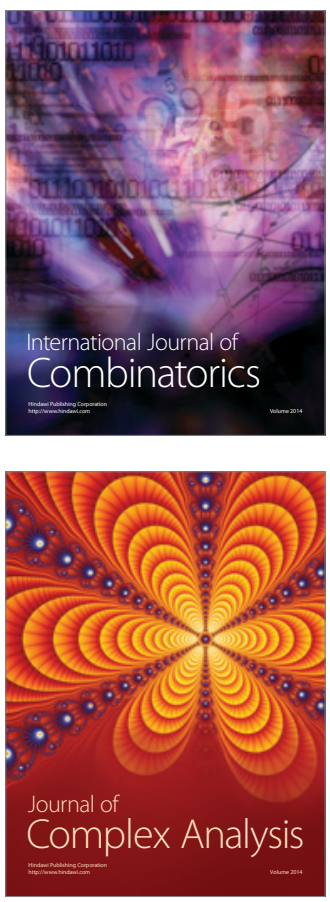

International Journal of

Mathematics and

Mathematical

Sciences
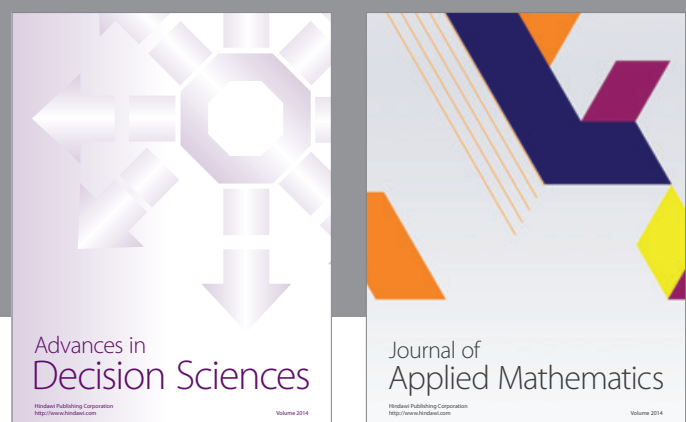

Journal of

Applied Mathematics
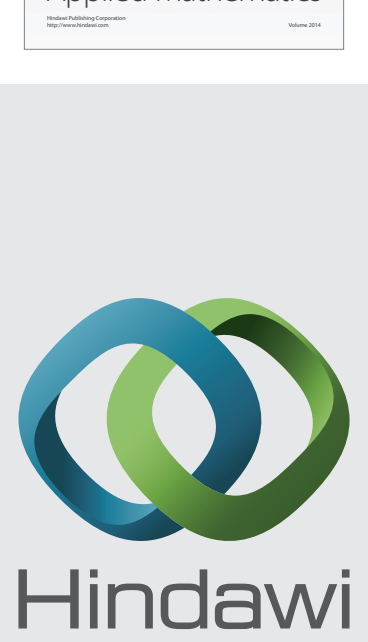

Submit your manuscripts at http://www.hindawi.com
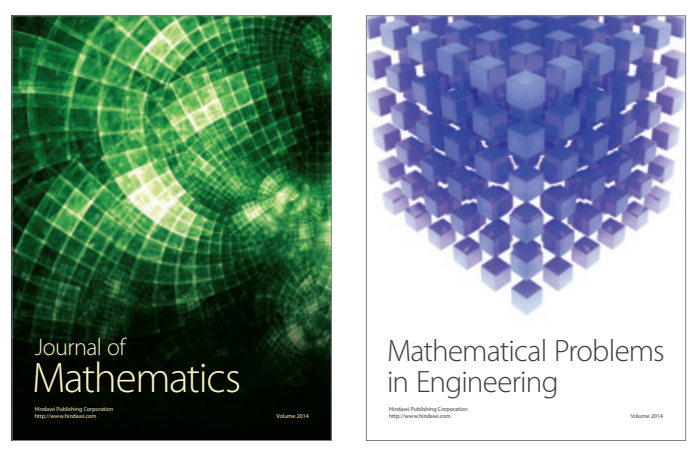

Mathematical Problems in Engineering
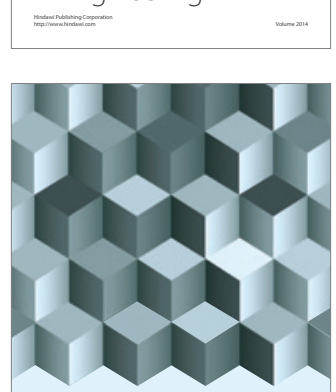

Journal of

Function Spaces
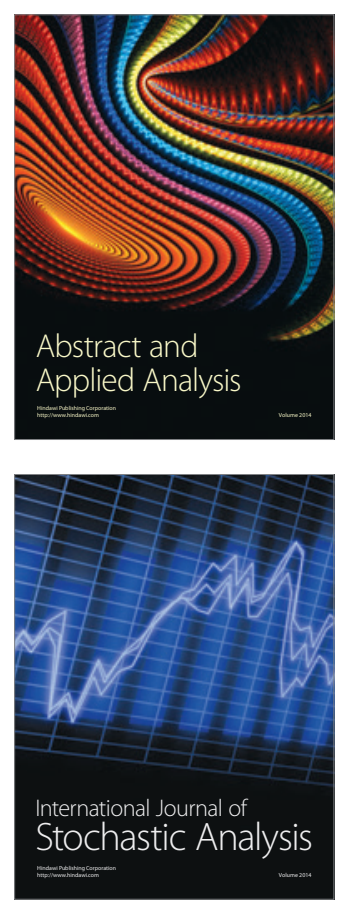

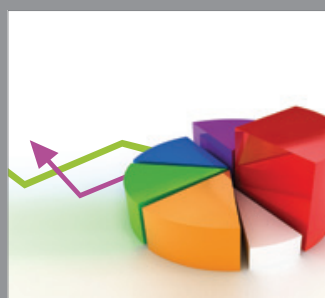

ournal of

Probability and Statistics

Promensencen
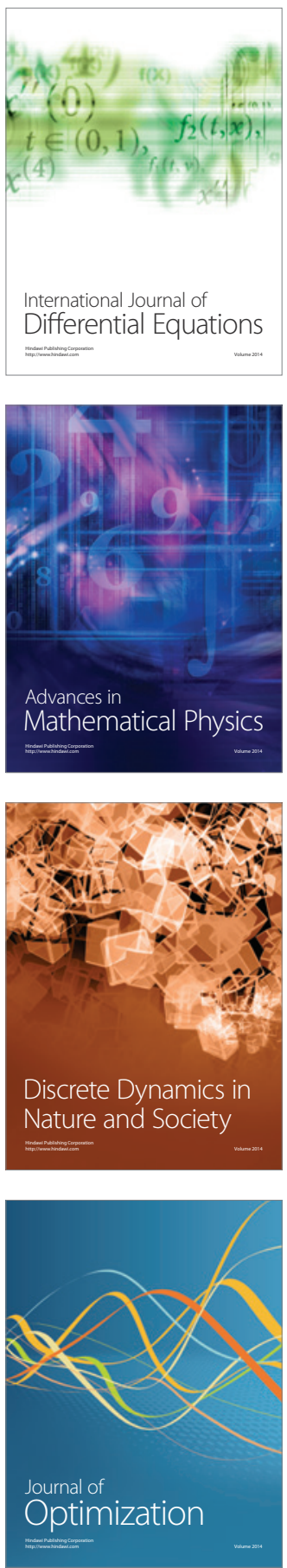